\title{
Work in Progress: Peer-Induced Competition Among Design Teams - Do Weekly Updates Among Leaders Accelerate Progress?
}

\section{Dr. Mary Staehle, Rowan University}

Dr. Mary Staehle is an Associate Professor and Undergraduate Program Chair of Biomedical Engineering at Rowan University. Before joining the faculty at Rowan in 2010, Dr. Staehle worked at the Daniel Baugh Institute for Functional Genomics and Computational Biology at Thomas Jefferson University and received her Ph.D. in chemical engineering from the University of Delaware. Her research is in the area of biomedical control systems, specifically neural regeneration. Dr. Staehle is also particularly interested in biomedical and chemical engineering education.

\section{Dr. Erik Brewer}

Erik Brewer is a Visiting Assistant Professor in the Biomedical Engineering Department at Rowan University, and Chief Scientist of ReGelTec, a biomedical start-up based in Mullica Hill, NJ. Prior to joining Rowan, Erik worked at Merck Research Labs in West Point, PA. Erik earned his Ph.D. in Chemical Engineering at Drexel University. His research interests are in drug delivery and biomaterials. 


\section{Work in Progress - Peer-Induced Competition Among Design Teams: Do Weekly Updates Among Leaders Accelerate Progress?}

\section{Introduction}

In the Rowan University Department of Biomedical Engineering, we offer a yearlong, teambased longitudinal Biomedical Engineering design course involving junior and senior students. Through this course, student teams interact with clinicians and industry experts outside of the university in a professional setting, and work to fulfill an unmet need in the medical field via engineering design within realistic economic, social, ethical, and manufacturability constraints. Previous work has shown that active engagement in the design process for actual, real-world problems like these reinforces concepts and improves learning [1,2]. In our course, each team is actively engaged in the design process throughout the yearlong course, which culminates in the development of a prototype or product.

In addition to the engineering design component, the course emphasizes technical and interpersonal communication. As in other similar design programs [3], student teams communicate their progress and results in various formats including a design history file, structured advisory committee meetings, end-of-semester public presentations, and manuscriptstyle final papers. Furthermore, they develop the interpersonal skills necessary to communicate with stakeholders and to work on multidisciplinary teams. All engineering students in the Henry M. Rowan College of Engineering at Rowan University are required to take a similar course, and these courses are structured to encourage multidisciplinary teams, which have been shown to ultimately produce higher-quality products [4]. Most of the biomedical engineering teams considered herein are composed primarily of biomedical engineering students, but we also include students from other engineering disciplines if their expertise would enhance the progress of the project. These out-of-discipline students apply to discipline-specific "openings" on the team and are matched via a college-wide optimization of student project placement.

In previous offerings of the course, we observed that teams suffered from undefined leadership, unstructure communication, and an inability to benchmark or evaluate their progress. Therefore, we have recently implemented a Team Leader model for these design teams.

\section{Team Leaders}

The efficacy and benefits of the Team Leader model have been described previously by others $[3,5,6]$. Similarly, we employ an application process to select Team Leaders: All rising seniors enrolled in the course are invited to apply via submission of an interest statement, résumé, and statement of qualifications. Finalists are interviewed by the course faculty advisors, and positions are offered to match the number of available projects. Projects are submitted and recruited from partnering clinicians and industrial partners, as well as biomedical engineering start-up companies in the area. All projects are then vetted carefully by Biomedical Engineering faculty for scope, feasibility, and academic potential. The final project list is developed based on the student enrollment and perceived potential of the projects. Team Leaders are provided with a description of each available project and asked to rank their choices. The course faculty advisors then optimize the matching to provide one Team Leader per project. A similar matching process occurs for the non-Leader students in the course. 
Our Team Leader program involves class meetings that serve as a two-way channel for information exchange, and Leaders are responsible for presenting weekly or biweekly updates to the instructors and their Team Leader peers. In the first semester, Leaders were also asked to present about any teamwork issues, and the instructors, as well as other Leaders, provided feedback and suggestions for rectifying these issues. Presenting this to their peer Leaders allowed Leaders and their teams without personnel issues to learn from the challenges of other teams and to gain management skills.

Additionally, the Team Leaders were designated as the liaison between the team and the clinical advisor, were responsible for scheduling and organizing the advisory committee meetings, and were expected to disseminate timely information from the faculty to their teammates.

\section{Assessment of Perceptions of the Team Leader Model and Project Progress}

Although we are firm believers in the power of peer pressure for performance enhancement, we were surprised to observe that an apparent peer-induced competition has accelerated progress globally among the design teams. We were not surprised to see the straggling teams improve based on knowledge of their team's progress relative to the other teams, but we observed a universal push toward project acceleration based on this apparent competition. Leaders who perceived their team as lagging behind another team's progress in any capacity (however minor) have redoubled their efforts to catch up and surpass the other teams.

To determine whether this "competition effect" is real or merely a perception by the instructors, we administered a survey of Team Leaders $(n=8)$. The 11-question online survey was distributed via Qualtrics ${ }^{\circledR}$, and $75 \%$ of the Leaders completed the survey. In the first portion of the survey, Leaders were asked to identify the biggest drivers and detractors of progress in their projects, both in terms of the academic requirements and otherwise. These were open-ended questions. The second portion asked the Leaders to rank seven elements of the course in order of decreasing influence on project progression: frequent updates at Team Leader meetings, course faculty advisor and advisory committee meetings, explicit deadlines, having specific requirements in the design history file, having an advisory committee, keeping up with the other teams, and other. In the third portion of the survey, Leaders were asked a sequence of Likert-scale questions regarding the Team Leader model and perceptions of competition therein, as well as two openended questions directed at the influence of the Team Leader weekly updates on their project progression. The survey settings did not allow revisions of previous answers, so the final portion of the survey provided Leaders with an opportunity to add any final comments about factors that enhanced or detracted from their team's progress.

We also administered an online Qualtrics ${ }^{\circledR}$ survey of non-Team Leader students in the course $(n=20)$. Eighty percent of students completed this survey. Questions on the non-Team Leader survey were very similar to those of the Team Leader survey except that the Likert-scale questions were focused more on the influence of the Team Leader, and students were not asked to comment on Team Leader weekly updates.

\section{Results}

In the initial, open-ended portion of the survey, Team Leaders and non-Team Leaders alike 
identified a variety of concrete deliverables that were beneficial in advancing their progress, and they listed the impact and influence of those deliverables as the primary non-academic drivers toward progress. While they felt they were beneficial, they also noted that the time required to complete these deliverables was the greatest obstacle toward progress. No students mentioned competition or anything related to measuring progress against other teams.

Team Leaders and Non-Team Leaders were asked to rank the influence of several course elements in pushing progress $(1=$ most influential, $7=$ least influential). Table 1 shows the studentreported average rankings of these course elements. The results mimic the answers provided in the open-ended portion, and interestingly, "keeping up with other teams" was consistently ranked as the least influential of the named categories.

Table 1: Student-Reported Average Rankings of Course Elements that Pushed Progress (1= Most Influential, 7=Least Influential; Team Leaders $n=6$, Non-Team Leaders $n=16$ )

\begin{tabular}{|c|c|c|c|}
\hline TEAM LEADERS & $\begin{array}{c}\text { Avg } \\
\text { Ranking }\end{array}$ & NON-TEAM LEADERS & $\begin{array}{c}\text { Avg } \\
\text { Ranking }\end{array}$ \\
\hline Having explicit deadlines & 1.83 & Having a Team Leader & 2.75 \\
\hline $\begin{array}{l}\text { Having specific requirements in the Design } \\
\text { History File }\end{array}$ & 2.67 & Having explicit deadlines & 3.06 \\
\hline $\begin{array}{l}\text { Course faculty advisor and advisory committee } \\
\text { meetings }\end{array}$ & 4.0 & $\begin{array}{l}\text { Course faculty advisor and advisory committee } \\
\text { meetings }\end{array}$ & 3.06 \\
\hline Having an advisory committee & 4.17 & Having an advisory committee & 3.19 \\
\hline Frequent updates at Team Leader meetings & 4.5 & $\begin{array}{l}\text { Having specific requirements in the Design } \\
\text { History File }\end{array}$ & 4.13 \\
\hline Keeping up with other teams & 4.67 & Keeping up with the other teams & 5.56 \\
\hline Other & 6.17 & Other & 6.25 \\
\hline
\end{tabular}

Table 2 shows the weighted averages of responses to the Likert-scale questions about the Team Leader model. Interestingly, Team Leaders and non-Team Leaders did not respond that competition or informed benchmarking against other teams were perceived factors or important in their progress. Rather, their responses to these Likert-scale questions and the subsequent short answer questions indicate that they do not perceive competition, and they suggest that any enhancement in progress and performance was likely because of a more structured sequence of required deliverables and the desire to have something to present at the weekly Team Leader meetings rather than a desire to "keep up with other teams" because of the Team Leader meetings. While it would be expected for non-team leaders to have little incentive to keep up with other teams, as they have little or no formal opportunity to evaluate other teams, we were surprised that "keeping up with other teams" was consistently ranked by team leaders as the least influential of the named categories.

\section{Conclusion}

When taken together, our preliminary assessment of the presence and role of competition due to weekly peer updates in Team Leader meetings suggests that students do not perceive any competition, and that either we have misinterpreted our perceptions or that the students are reacting to a subliminal competition that inherently promotes higher achievement in academic coursework more globally and thus they do not perceive any additional competition in this course. 
Table 2: Weighted Average Results of Likert-scale Questions for Team Leaders and non-Team Leaders ( $1=$ Strongly Agree, $2=$ Agree, $3=$ Somewhat Agree, 4=Neither Agree nor Disagree, $5=$ Somewhat Disagree, $6=$ Disagree, $7=$ Strongly Disagree)

\begin{tabular}{|c|c|c|c|}
\hline TEAM LEADER QUESTION & Avg & NON-TEAM LEADER QUESTION & Avg \\
\hline I am satisfied with the rate of progress in my team. & 6.00 & I am satisfied with the rate of progress in my team. & 5.63 \\
\hline I like the Team Leader model. & 5.67 & I like the Team Leader model. & 5.56 \\
\hline $\begin{array}{l}\text { I feel my group's progress is comparable to the progress of } \\
\text { most groups. }\end{array}$ & 5.67 & $\begin{array}{l}\text { I feel my group's progress is comparable to the progress of } \\
\text { most groups. }\end{array}$ & 5.44 \\
\hline $\begin{array}{l}\text { The Team Leader meetings have been helpful to progress in } \\
\text { my team. }\end{array}$ & 5.33 & Having a Team Leader has helped our team's progress. & 5.94 \\
\hline I tell my team about what other teams are doing. & 5.17 & $\begin{array}{l}\text { My team leader helps us learn about what other teams are } \\
\text { doing. }\end{array}$ & 4.81 \\
\hline $\begin{array}{l}\text { The fact that I know what the other teams are doing makes it } \\
\text { more competitive. }\end{array}$ & 5.17 & $\begin{array}{l}\text { The fact that my Team Leader knows what the other teams } \\
\text { are doing makes it more competitive. }\end{array}$ & 4.31 \\
\hline $\begin{array}{l}\text { We have done at least one thing in our project just because } \\
\text { another team did it and we felt as though we had to. }\end{array}$ & 4.50 & $\begin{array}{l}\text { We have done at least one thing in our project just because } \\
\text { another team did it and we felt as though we had to. }\end{array}$ & 3.75 \\
\hline
\end{tabular}

\section{Works Cited}

[1] J. P. Terpenny, W. G. Sullivan, H. Singh, and K. Sward, "Utilizing the Internet to Improve Student Learning in a First Course in Engineering Economy with Real-World Unsolved Problems in Collaboration with Industry," 2002.

[2] M. R. Goldberg and J. L. Pearlman, "Best practices for team-based assistive technology design courses," Ann. Biomed. Eng., vol. 41, no. 9, pp. 1880-1888, 2013.

[3] Allen, R. H., Acharya, S., Jancuk, C., \& Shoukas, A. A. (2013). Sharing best practices in teaching biomedical engineering design. Annals of biomedical engineering, 41(9), 18691879.

[4] J. P. Terpenny, R. M. Goff, M. R. Vernon, and W. R. Green, "Utilizing Assistive Technology Design Projects and Interdisciplinary Teams to Foster Inquiry and Learning in Engineering Design," vol. 11, 2006.

[5] John, W., \& Artin, S., \& Allen, R., \& Aronhime, L. (2003), Integrating Biomedical Engineering With Entrepreneurship And Management At The Undergraduate Level Proceedings of the 2003 ASEE Annual Conference and Exposition, Nashville, Tennessee.

[6] Logsdon, E. A., \& Allen, R., \& Durr, N. J., \& Nguyen, H. (2017), A Team Leader Model for Biomedical Engineering Design Team Project-Definition Training and Scalable Clinical Observation (Work in Progress) Proceedings of the 2017 ASEE Annual Conference \& Exposition, Columbus, Ohio. 